\title{
An assessment of stigma and human right violations among men who have sex with men in Abuja, Nigeria
}

Susanne Strömdahl ${ }^{1,2^{*}}$ (D), Abimbola Onigbanjo Williams ${ }^{3}$, Bede Eziefule ${ }^{3}$, Godwin Emmanuel ${ }^{3}$, Stella Iwuagwu ${ }^{3}$, Oliver Anene ${ }^{4}$, Ifeanyi Orazulike ${ }^{4}$, Chris Beyrer ${ }^{1}$ and Stefan Baral ${ }^{1}$

\begin{abstract}
Background: There have been several barriers in effectively engaging men who have sex with men for STI/HIV prevention and treatment programming in Nigeria including social stigma, policies, and laws criminalizing same-sex practices. The objective of this study was to describe the human rights context for MSM in Abuja and characterize factors associated with having had a genital ulcer disease in the previous 12 months, a health outcome associated with increased risk of HIV acquisition and transmission.

Methods: A convenience sample of 297 men reporting ever having had anal intercourse with another man participated in the study in 2008. A structured survey instrument including sexual risk behaviour for STI/HIV, disclosure of sexual orientation, perceived and enacted human rights violations were performed. Descriptive and inferential data analyses were conducted using Stata11 software.

Results: $36 \%$ reported having been discriminated due to sexual orientation and $17 \%$ reported being afraid to walk the streets of their community. Enacted rights violations included $41 \%$ having been blackmailed, $36 \%$ been beaten, $13 \%$ been denied housing, and $11 \%$ been jailed due to sexual orientation. Having been blackmailed due to sexual orientation (aOR 3.40, 95\% Cl: 1.35-8.56) was significantly associated with reporting having had a genital ulcer in the last 12 months. Having been beaten due to sexual orientation ( $\mathrm{OOR} 2.36,95 \% \mathrm{Cl}: 0.96-5.82$ ) was moderately significantly associated with reporting having had a genital ulcer in the last 12 months.

Conclusions: High levels of experienced stigma, discrimination and human rights violations among MSM in Abuja was reported, constituting structural risks that are linked to sexual risk behaviour for STI/HIV. Given data on the high prevalence and incidence of HIV among MSM in Abuja, these findings reinforce the need for structural interventions to mediate access to STI/HIV prevention and treatment services.
\end{abstract}

Keywords: Men who have sex with men, Stigma, Human rights violations, HIV, STI

\section{Background}

Studies have consistently demonstrated across diverse economic and geographical contexts that stigma and human rights violations disproportionately affect gay men and other men who have sex with men (MSM). Perceived and enacted stigma have been found to be associated with sexual high risk behaviour for HIV and decreased rates of

\footnotetext{
* Correspondence: sstromd1@jhu.edu; susanne.stromdahl@medsci.uu.se ${ }^{1}$ Centre for Public Health and Human Rights, Department of Epidemiology, Johns Hopkins Bloomberg School of Public Health, Baltimore, USA

${ }^{2}$ Department of Medical Sciences, Section of Infectious Diseases, Uppsala University, Uppsala, Sweden

Full list of author information is available at the end of the article
}

HIV testing among MSM ranging from Southern Africa to Eastern Asia to Western Europe [1-4].

Same sex practices are criminalized under federal sodomy laws and punishable by lengthy prison sentences and even death by stoning in twelve of Nigeria's 36 States [5]. The Same Sex Marriage Prohibition Act, was signed on Jan 13th 2014 further criminalizing same-sex relationships, public display of same-sex amorous relationships and membership of gay clubs and organizations with penalties of up to 14 years of incarceration [6]. Following the approval of the bill, there have been

(C) The Author(s). 2019 Open Access This article is distributed under the terms of the Creative Commons Attribution 4.0 International License (http://creativecommons.org/licenses/by/4.0/), which permits unrestricted use, distribution, and reproduction in any medium, provided you give appropriate credit to the original author(s) and the source, provide a link to the Creative Commons license, and indicate if changes were made. The Creative Commons Public Domain Dedication waiver (http://creativecommons.org/publicdomain/zero/1.0/) applies to the data made available in this article, unless otherwise stated. 
reported increases in the arrests of gay men and other MSM in Nigeria [7].

HIV prevalence in Nigeria has been estimated to be $3.1 \%$ in 2016 [8]. Due to Nigeria's large population of 186.5 million inhabitants this translates to that the country holds about $10 \%$ of the global burden of HIV [9]. The 2014 Integrated Biological and Behavioural Surveillance Study (IBBSS) among MSM estimated HIV prevalence to be $22.9 \%$, an increase compared to the IBBSS 2010 that reported a HIV prevalence of $17.2 \%$ [10, 11]. These estimates are about five times higher than the HIV prevalence in the general population $[12,13]$.

A prospective cohort study of MSM, the TRUST cohort, recruited 862 MSM in Nigeria between 2013 and 16 and reported a 55\% prevalence of HIV. Chlamydia was diagnosed among 17\% in Abuja and 18\% in Lagos and gonorrhoea among 19\% in Abuja and 26\% in Lagos indicating a high burden of sexually transmitted infections (STI) [14]. Incident STI was found to be associated with HIV infection [15].

Sexual risk behaviours for HIV and STIs overlap, with the most efficient mode of HIV transmission through sexual contact being condomless anal sex with a serodiscordant viremic person [16]. Genital ulcerative diseases (GUD) are caused by STIs and introduces a breakage in the genital mucosa and genital bleeding which increases the acquisition risk for HIV $[17,18]$. GUD further enhances HIV transmission from an HIV-infected individual by increasing genital HIV shedding [19-22].

Health care facilities play an important role for successful antiretroviral treatment (ART) to achieve viral suppression and thereby also limiting onwards transmission, known as Treatment as Prevention (TasP). The TRUST MSM cohort in Nigeria reported that disclosure of being MSM to a health care provider was associated with treatment adherence and HIV viral load suppression at 6 month follow up [23]. After the Same Sex Marriage Prohibition Act was passed in 2014 a substantial part of the TRUST cohort was lost to follow up. Those MSM remaining in the cohort reported a significant increase in fear of seeking health care [24]. Fear of seeking health care has been reported in other African contexts as well, $17 \%$ among MSM in Malawi, Namibia and Botswana reported fear of seeking health care. Having experienced discrimination due to sexual orientation was found to be associated with fear of seeking health care and was more common among those on ART [1].

Considering the high HIV incidence and prevalence reported among MSM in Nigeria, Pre Exposure Prophylaxis for HIV (PrEP) hold promise to help curb the epidemic [25]. However PrEP is dependent on that MSM are willing to visit health care facilities for regular HIV/ STI testing and follow-up. Thereby fear of seeking health care and fear of disclosing as MSM may act as a barrier to PrEP uptake. These data points towards that stigma and criminalization play an important role in the HIV/ STI epidemic among MSM in Nigeria, acting as a structural barrier to HIV/STI prevention and treatment.

The objective of this study was to describe the human rights contexts for MSM in Abuja in 2008, before the Same Sex Marriage Prohibition Act was passed. In addition, to characterize factors associated with reporting having had a GUD in the previous 12 months, a health outcome that is associated with HIV acquisition and transmission risk. A modified social ecological model (MSEM) was used to assess HIV risk [26]. This study was implemented in partnership between the Centre for Right to Health, a Non Governmental Organization working for access to health care for vulnerable groups, and Alliance Rights Nigeria, a Non Governmental Organization focused on addressing the needs of MSM in Abuja.

\section{Methods}

\section{Study population and accrual methods}

The study method has been described in detail in the parent study (17). Briefly, the study was performed in 2008 and includes a convenience sample of 297 MSM in Abuja, Nigeria. Inclusion criteria included men aged $18-65$ years old, living in Abuja who self-reported ever having had anal intercourse with another man. A structured survey face to face with a trained peer in a safe and private environment to ensure confidentiality was performed. The survey included modules on socio-demographic characteristics, sexual orientation and practices, condom use during last six months, number of partners, and knowledge of HIV/ STIs. A module of the survey was dedicated to disclosure of sexual orientation, stigma, discrimination, and perceived and enacted human rights abuses. The MSEM model was used to guide the data collection and analysis including different levels of HIV/STI risk contexts (29). Informed consent was obtained from all participants.

\section{Statistical analysis}

Exploratory, descriptive and inferential data analysis was conducted using Stata 11.1 software (College Station, Texas). Descriptive statistics with chi-square and t-test were used for socio-demographic characteristics, disclosure of sexual orientation, enacted and perceived human rights violations and reported genital ulcer in past 12 months. The predictor variables were dichotomized and univariate binomial logistic regression and t-test were used to identify factors associated with reported genital ulcer in the last 12 months.

Fifthteen variables representing multi-levels of HIV/STI risk in the MSEM model were tested for association with self-reported genital ulcer in the last 12 months [26]. Backward elimination with a $p$-value set to 0.1, locking the variables age and tertiary education in the model due 
to being hypothesized confounder in the conceptual framework, was used to determine which variables to include in the multivariate model. The Hosmer-Lemeshow test was performed to assure goodness of fit [27]. The likelihood ratio test was used to test for interaction between the predicting variables; blackmailed due to sexual orientation and having been beaten due to sexual orientation. The stability of the model was confirmed by Akaike information criterion (AIC) values [28]. Variables with a $(p<0.05)$ were considered significantly associated with the outcome and variables with a $(p<0.1)$ were considered moderately significantly associated with the outcome; self-reported genital ulcer in the previous 12 months.

\section{Results}

Socio-demographic characteristics of the study population

Table 1 describes the characteristics of the 297 MSM who participated in the study. Almost all MSM participating in this study, 95\% $(n=282 / 297)$ had a secondary school or higher educational level. However, only 59\% ( $n=175 / 297)$ were employed. Age of participants ranged between 18 and 45 years old with a median of 26. All three large ethnic groups in Nigeria were represented; Igbo $37 \%(n=107 / 289)$, Yoruba $18 \%(n=53 / 289)$, and

Table 1 Socio-demographic Characteristics of MSM in Abuja

\begin{tabular}{|c|c|c|}
\hline Characteristic & Percentage & Absolute \# \\
\hline Age $(n=295)$ & Mean 26 Median 26.05 & Range $18-45$ \\
\hline \multicolumn{3}{|l|}{ Education } \\
\hline Primary school & $5.05 \%$ & $15 / 297$ \\
\hline Secondary school & $49.83 \%$ & $148 / 297$ \\
\hline Tertiary or vocational school & $45.12 \%$ & $134 / 297$ \\
\hline Employment & $58.92 \%$ & $175 / 297$ \\
\hline \multicolumn{3}{|l|}{ Religion } \\
\hline Christian & $78.17 \%$ & $222 / 283$ \\
\hline Muslim & $17.25 \%$ & $49 / 283$ \\
\hline Traditional & $0.7 \%$ & $2 / 283$ \\
\hline No religion & $3.53 \%$ & $10 / 283$ \\
\hline \multicolumn{3}{|l|}{ Ethnic group } \\
\hline Yoruba & $18.34 \%$ & $53 / 289$ \\
\hline Igbo & $37.02 \%$ & $107 / 289$ \\
\hline Hausa & $15.22 \%$ & $44 / 289$ \\
\hline Other & $29.41 \%$ & $85 / 289$ \\
\hline \multicolumn{3}{|l|}{ Sexual self identification } \\
\hline heterosexual/straight & $1.34 \%$ & $4 / 299$ \\
\hline homosexual/gay & $35.45 \%$ & $106 / 299$ \\
\hline bisexual & $63.21 \%$ & 189/299 \\
\hline transgender & $0 \%$ & 0/299 \\
\hline Genital ulcer in past 12 months & $18.7 \%$ & $54 / 289$ \\
\hline
\end{tabular}

Hausa $15 \%(n=44 / 289)$. Only $15 \%(n=43 / 294)$ reported belonging to a MSM community-based association. A fifth of the study population,19\% $(n=54 / 289)$, reported having had a genital ulcer in the last 12 months.

\section{Disclosure of sexual orientation}

$15 \%(n=44 / 288)$, reported that they were open regarding their sexual orientation in their community. Somewhat less, $11 \%(n=32 / 293)$ reported that their community was aware of their sexual orientation. One fourth, $25 \%(n=72 /$ 293) had disclosed their sexual orientation to their immediate family. About one third, 28\% $(n=84 / 297)$ had disclosed their sexual orientation to a health worker. Further details are described in Table 2.

\section{Stigma, discrimination and human rights violations}

As described in Table 3, more than a third, 36\% ( $n=$ $102 / 284$ ) reported having been discriminated due to their sexual orientation. Close to half, $41 \%(n=116 / 286)$ had been blackmailed due to their sexual orientation. Almost one third, 28\% ( $n=81 / 289)$ had been arrested and a tenth,11\% ( $n=31 / 287)$ had been arrested due to their sexual orientation. 36\% (101/278) had been beaten due to their sexual orientation, $7 \%(n=20 / 278)$ by a family member and $8 \%(n=21 / 278)$ by a sexual partner. $3 \%(n$ $=9 / 278$ ) reported having been beaten by police or government officials due to their sexual orientation. About a fifth, $18 \%(n=51 / 281)$ reported having been raped of which $24 \%(n=12 / 51)$ reported rape to authorities/police. Only $1 \%(n=2 / 295)$ had been denied health care due to their sexual orientation.

\section{Associations with having had a genital ulcer in the last 12 months}

In the univariate analysis described in Table 4, the following variables were found to be significantly associated with having had a GUD in the previous 12 months; having received money/gifts for sex (OR 2.67, 95\%CI: 1.30-5.48), been denied housing due to sexual orientation (OR 2.98, 95\%CI: 1.39-6.41), been arrested (2.13, 95\%CI: 1.14-3.96), been arrested due to sexual orientation (OR 3.88, 95\%CI:

Table 2 Disclosure of sexual orientation among MSM in Abuj

\begin{tabular}{lll}
\hline Characteristic & Percentage & Absolute \# \\
\hline Open to community & $15.28 \%$ & $44 / 288$ \\
$\begin{array}{l}\text { Community aware of sexual orientation } \\
\begin{array}{l}\text { Disclosed sexual orientation to } \\
\text { immediate family }\end{array}\end{array}$ & $10.92 \%$ & $32 / 293$ \\
$\begin{array}{l}\text { Disclosed sexual orientation to } \\
\text { extended family }\end{array}$ & $12.85 \%$ & $37 / 293$ \\
$\begin{array}{l}\text { Disclosed sexual orientation to } \\
\text { health worker }\end{array}$ & $28.28 \%$ & $84 / 297$ \\
$\begin{array}{l}\text { Disclosed sexual orientation to } \\
\text { religious leader }\end{array}$ & $18.06 \%$ & $52 / 288$ \\
\hline
\end{tabular}


Table 3 Human rights contexts

\begin{tabular}{lll}
\hline Characteristic & Percentage & Absolute \# \\
\hline Discriminated due to sexual orientation & $35.92 \%$ & $102 / 284$ \\
Denied housing due to sexual orientation & $12.63 \%$ & $36 / 285$ \\
Denied health care due to sexual orientation & $0.68 \%$ & $2 / 295$ \\
Discriminated in place of worship & $25.42 \%$ & $15 / 59$ \\
Afraid to walk in their community & $15.27 \%$ & $42 / 275$ \\
Blackmailed due to sexual orientation & $40.56 \%$ & $116 / 286$ \\
Have been arrested/jailed & $28.20 \%$ & $81 / 289$ \\
Have been arrested/jailed due to sexual orientation & $10.80 \%$ & $31 / 287$ \\
Access to condoms in jail & $1.45 \%$ & $1 / 69$ \\
Beaten due to sexual orientation & $36.33 \%$ & $101 / 278$ \\
Beaten by police/government officials due to sexual orientation & $3.24 \%$ & $9 / 278$ \\
Beaten by family member due to sexual orientation & $7.19 \%$ & $20 / 278$ \\
Beaten by sexual partner & $7.55 \%$ & $21 / 278$ \\
Been raped & $18.15 \%$ & $23.53 \%$ \\
Reported rape & $2.63 \%$ & $1 / 38$ \\
Prosecuted rape & & \\
\hline
\end{tabular}

1.75-8.60), beaten due to sexual orientation (OR 3.68, 95\%CI: 1.96-6.91), blackmailed due to sexual orientation (OR 3.54, 95\%CI 1.89-6.60), and been raped (OR 2.30, 95\%CI: 1.15-4.58). The following variables were found to be significantly inversely associated with having had a GUD in the previous 12 months; tertiary schooling (OR 0.29 , 95\%CI:0.15-0.58), knowledge that HIV/STIs can be transmitted through unprotected anal intercourse (OR 0.34, 95\%CI: 0.13-0.89). In the multivariate analysis, having been blackmailed due to sexual orientation (aOR 3.40,
95\%CI: 1.35-8.56) was significantly associated with having had a GUD in the previous 12 months. Having been beaten due to sexual orientation (aOR 2.36, 95\%CI:0.965.82) was moderately significantly associated with having had a GUD in the previous 12 months.

\section{Discussion}

Human rights contexts were challenging for gay men and other MSM in Nigeria in 2008. Since this study was performed same sex practices has been further criminalized in

Table 4 Associations of genital ulcer in previous 12 months among MSM in Abuja

\begin{tabular}{llll}
\hline Variable & Prevalence (Absolute\#) & Univariate & Multivariate \\
\hline Age $>26$ & $45 \%(n=134 / 295)$ & $1.53(0.84-2.78)$ & $1.12(0.56-2.24)$ \\
Tertiary education & $45 \%(n=134 / 297)$ & $0.29(0.15-0.58)^{* *}$ & $0.55(0.25-1.19)$ \\
Employed & $59 \%(n=175 / 297)$ & $1.41(0.76-2.64)$ \\
Consistent condom use with male partners & $53 \%(n=155 / 290)$ & $0.65(0.36-1.19)$ \\
Knowledge of HIV/STI transmission risk at condomless anal sex & $91 \%(n=200 / 220)$ & $0.34(0.13-0.89)^{* *}$ \\
Bisexual concurrency & $66 \%(n=179 / 271)$ & $0.78(0.40-1.54)$ \\
Ever HIV-tested & $65 \%(n=180 / 276)$ & $0.56(0.30-1.07)$ \\
Received money/gifts for sex & $62 \%(n=169 / 274)$ & $2.67(1.30-5.48)^{* *}$ \\
Denied housing due to sexual orientation & $13 \%(n=36 / 285)$ & $2.98(1.39-6.41)^{* *}$ \\
Afraid to walk the streets of their community & $15 \%(n=42 / 275)$ & $1.96(1.06-3.63)$ \\
Been arrested & $28 \%(n=81 / 289)$ & $2.13(1.14-3.96)^{* *}$ \\
Been arrested due to sexual orientation & $11 \%(n=31 / 287)$ & $3.88(1.75-8.60)^{* *}$ \\
Beaten due to sexual orientation & $36 \%(n=101 / 278)$ & $3.68(1.96-6.91)^{* *}$ \\
Blackmailed & $41 \%(n=116 / 286)$ & $3.54(1.89-6.60)^{* *}$ \\
Raped & $18 \%(n=51 / 281)$ & $2.30(1.15-4.58)^{*}$ \\
\hline
\end{tabular}


2014 [24]. Concurrently, the evidence base of a sustained and disproportionate burden of HIV and STIs among these men is growing [11, 14, 23]. The data presented here highlight the statistically significant relationship between perceived and enacted rights violations and GUD.

The data concludes that having been blackmailed or beaten due to sexual orientation as MSM is associated with having had a GUD recently, which increases the risk of HIV transmission at condomless sex. High levels of stigma, perceived and enacted human rights violations were found. More than a third reported having been beaten due to their sexual orientation. Two fifths of participants reported having been blackmailed due to sexual orientation, supporting previous similar findings among MSM in Malawi, Botswana, Namibia and Nigeria [1, 4, 29]. Recent data suggest that fear of seeking health care and disclosing as MSM remain barriers to uptake of HIV/STI prevention and treatment in Nigeria [24].

As HIV prevalence among MSM in Abuja has been estimated to be as high as $30-50 \%$, ART is a core component of combination HIV prevention programming for MSM $[11,14]$. Structural stigma and criminalization poses a significant barrier to TasP uptake among MSM limiting the potential effect on the HIV epidemic. As reported from the TRUST cohort study there was a significant drop out among MSM participants on ARV after the passing of the Same Sex Marriage Prohibition Act in 2014 [24]. The on-going TRUST cohort and other studies are needed to explore how to overcome these barriers in settings where same sex practices are criminalized.

In addition PrEP is becoming available for MSM in some African settings, both South Africa and Kenya have approved PrEP for MSM [30]. Due to the high burden of HIV among MSM in Nigeria PrEP would be most beneficial for sero negative MSM at risk of HIV. Disclosure of same sex practices to health care providers is key to be able to do appropriate risk stratification and prescribe PrEP for those in need. To target those men in need of PrEP also holds relevance to ensure that PrEP programmes are cost-effective. Encouragingly, about a third had disclosed their sexual orientation to a health provider and only $1 \%$ of MSM had been denied health care. Similar results were reported among MSM in Malawi, Botswana and Namibia [1].

When applying the MSEM model to MSM in Nigeria, we find HIV risks at all layers including individual, network, community and public policy [26]. At the individual risk level, about a fifth of MSM participating in this study reported having had a GUD in the past 12 months. At the social network level, about a fifth had disclosed their sexual orientation to immediate family, which could provide social support for the individual. However, about a tenth had been beaten by a family member due to their sexual orientation suggesting that disclosure to family might not offer social support. The high prevalence of HIV and STIs reported in Abuja suggest a high HIV risk within the sexual network $[14,31]$. At the public policy level, laws criminalizing MSM organizations create a barrier to peer HIV/ STI prevention programmes and peer support programmes for adherence to TasP. Finally, a very high level of enacted human rights violations were found in this study, stressing that factors at the community level poses a barrier for MSM to access needed HIV/STI services. Thereby we also find structural stigma towards MSM embedded in all ecological layers, including the individual, social network, community and public policy level. A recent study among MSM in Togo stressed further that the network, community and policy level factors was associated with HIV infection [32].

The data reported here implicates that structural stigma, perceived and enacted human rights violations are barriers to uptake of health services among MSM. As well as acting as barriers to implement improved public health programming for this population. Future comprehensive HIV preventions for MSM should include components on human rights and stigma for the individual MSM, at the social network level through peer support groups, the community level through awareness campaigns, and to aspire to impact the public policy level and lead to a movement towards equal rights [33]. Further studies can contribute by making data on HIV, stigma and human rights available to highlight the current situation among MSM in Nigeria.

The recruitment for this study was performed as a convenience sample in 2008 , generalizability is thereby limited. Some years have passed since these data were collected and the legal climate in Nigeria has changed with harsher criminalization of same sex practices. Thereby these data highlight the human rights context among MSM in Abuja prior to these legal changes. External validity is further limited as this study was performed in Abuja, an urban centre in Nigeria. The study design is cross-sectional and thereby causality cannot be detected. Self-reported data includes a risk of reportingand social desirability- bias. The study was performed in collaboration with a MSM community and employed members of the MSM community at all stages of the study including design, instrument development and implementation to ensure safety of the participants and to minimize social desirability bias.

\section{Conclusion}

High levels of stigma, perceived and enacted human rights violations were reported among MSM in Abuja in 2008. Having been blackmailed or beaten due to sexual orientation was found to be associated with having had a GUD recently. Since 2008 the legal climate in Nigeria has changed with the passing of more punitive laws 
further criminalizing same sex practices. In addition, the HIV/STI epidemics remain at high prevalence levels among MSM. Fear of disclosing as MSM and fear of seeking health care construct barriers for uptake of HIV/ STI prevention including PrEP and universal coverage of ART among MSM at risk for and living with HIV, respectively. While efficacy data support the need for ART-based strategies at scale, studying implementation models of effective scaling is required given the sustained and increasing structural challenges to service provision for MSM in Nigeria.

\section{Abbreviations}

ART: Antiretroviral treatment; GUD: Genital ulcer disease; IBBSS: Integrated biological and behavioural surveillance study; MSEM: Modified social ecological model; MSM: Men who have sex with men; PrEP: Pre exposure prophylaxis for HIV; STI: Sexually transmitted infections; TasP: Treatment as prevention

\section{Acknowledgements}

The author team gratefully acknowledge the courage and hard work of the Nigerian LGBTI community, and thank study participants for partaking in this research.

\section{Funding}

This research project was funded by a grant from the Foundation for AIDS research (amfAR) to the Centre for Right to Health based in Abuja, Nigeria. The funder of this project had no role in the design of the study, data collection, analysis, interpretation of data, writing of the manuscript, or decision to publish the results. The effort of the team from the Centre for Public Health and Human Rights of the Johns Hopkins School of Public Health was provided in-kind.

\section{Availability of data and materials}

The datasets used and/or analysed during the current study are available from the corresponding author on reasonable request.

\section{Authors' contributions}

$\mathrm{SB}, \mathrm{AW}, \mathrm{BE}, \mathrm{SI}$ participated in the study's design and coordination, the interpretation of the data and helped to revise the manuscript. GE, BE, OA, IO carried out data collection activities, participated in the interpretation of the data, and helped to revise the manuscript. CB participated in the study design and coordination and helped to revise the manuscript for intellectual content. SS performed the data analysis, drafted the manuscript and participated in dissemination of findings in Nigeria. All authors approved the final manuscript.

\section{Ethics approval and consent to participate}

Ethical approval was granted by the Federal Capital Territory Health Research Ethics Committee in Abuja as well as by the IRB of Johns Hopkins Bloomberg School of Public Health. All participants signed a written informed consent form after having received information regarding the study.

\section{Consent for publication}

Not applicable.

\section{Competing interests}

The authors declare that they have no competing interests.

\section{Publisher's Note}

Springer Nature remains neutral with regard to jurisdictional claims in published maps and institutional affiliations.

\section{Author details}

${ }^{1}$ Centre for Public Health and Human Rights, Department of Epidemiology, Johns Hopkins Bloomberg School of Public Health, Baltimore, USA. 2Department of Medical Sciences, Section of Infectious Diseases, Uppsala University, Uppsala, Sweden. ${ }^{3}$ Centre for the Right to Health Nigeria $(\mathrm{CRH})$, Abuja, Nigeria. ${ }^{4}$ Alliance Rights Nigeria (ARN), Abuja, Nigeria.
Received: 1 September 2017 Accepted: 17 January 2019

Published online: 05 March 2019

\section{References}

1. Fay H, Baral SD, Trapence G, Motimedi F, Umar E, lipinge S, Dausab F, Wirtz A, Beyrer C. Stigma, health care access, and HIV knowledge among men who have sex with men in Malawi, Namibia, and Botswana. AIDS Behav. 2011;15(6):1088-97.

2. Neilands TB, Steward WT, Choi KH. Assessment of stigma towards homosexuality in China: a study of men who have sex with men. Arch Sex Behav. 2008;37(5):838-44.

3. Berg RC, Ross MW, Weatherburn P, Schmidt AJ. Structural and environmental factors are associated with internalised homonegativity in men who have sex with men: Findings from the European MSM Internet Survey (EMIS) in 38 countries. Soc Sci Med. 78:61-9.

4. Stahlman S, Sanchez TH, Sullivan PS, Ketende S, Lyons C, Charurat ME, Drame FM, Diouf D, Ezouatchi R, Kouanda $S$, et al. The prevalence of sexual behavior stigma affecting gay men and other men who have sex with men across sub-Saharan Africa and in the United States. JMIR Public Health Surveill. 2016:2(2):e35. https://doi.org/10.2196/publichealth.5824.

5. Carroll A, Itaborahy LP. State Sponsored Homophobia 2015: A world survey of laws: criminalisation, protection and recognition ofsame-sex love. Geneva: International Lesbian, Gay, Bisexual, Trans and Intersex Association; 2015. https://ilga.org/downloads/ILGA_State_Sponsored_Homophobia_ 2015.pdf.

6. Baral SD, Ketende S, Mnisi Z, Mabuza X, Grosso A, Sithole B, Maziya S, Kerrigan DL, Green JL, Kennedy CE et al: A cross-sectional assessment of the burden of HIV and associated individual- and structural-level characteristics among men who have sex with men in Swaziland. J Int AIDS Soc 2013, 16(Suppl 3):18768. doi: 187https://doi.org/10.17448/IAS.18716.18764.18768.

7. Karimi FD, Vladimir: Nigeria arrests gay 'suspects' under new law banning homosexuality. In: CNN.

8. Country Profile Nigeria [http://databank.worldbank.org/data/Niews/Reports/ ReportWidgetCustom.aspx?Report_Name=CountryProfile\&ld= b450fd57\&tbar=y\&dd=y\&inf $=n \& z m=n \&$ country $=N G A]$.

9. Nigeria [http://www.unaids.org/en/regionscountries/countries/nigeria].

10. Nigeria FMoHF: Nigeria integrated biological and Behavioural surveillance survey 2010. In.

11. Nigeria FMoH: Nigeria Integrated Biological and Behavioural Surveillance Survey 2014. In.; 2015.

12. Merrigan M, Azeez A, Afolabi B, Chabikuli ON, Onyekwena O, Eluwa G, Aiyenigba B, Kawu I, Ogungbemi K, Hamelmann C. HIV prevalence and risk behaviours among men having sex with men in Nigeria. Sex Transm Infect. 2011;87(1):65-70.

13. UNAIDS. Report on the global AIDS epidemic 2010. Geneva: United Nations; 2010.

14. Keshinro B, Crowell TA, Nowak RG, Adebajo S, Peel S, Gaydos CA, Rodriguez-Hart C, Baral SD, Walsh MJ, Njoku OS et al: High prevalence of HIV, chlamydia and gonorrhoea among men who have sex with men and transgender women attending trusted community centres in Abuja and Lagos, Nigeria. J Int AIDS Soc 2016, 19(1):21270. doi: 212https://doi.org/10. 27448/IAS.21219.21271.21270. eCollection 22016

15. Ramadhani HO, Liu H, Nowak RG, Crowell TA, Ndomb T, Gaydos C, Peel S, Ndembi N, Baral SD, Ake J, et al. Sexual partner characteristics and incident rectal Neisseria gonorrhoeae and chlamydia trachomatis infections among gay men and other men who have sex with men (MSM): a prospective cohort in Abuja and Lagos, Nigeria. Sex Transm Infect. 2017:2016-052798.

16. Baggaley RF, White RG, Boily MC. HIV transmission risk through anal intercourse: systematic review, meta-analysis and implications for HIV prevention. Int J Epidemiol. 39(4):1048-63.

17. Lewis DA, Muller E, Steele L, Sternberg M, Radebe F, Lyall M, Ballard RC, PazBailey G. Prevalence and associations of genital ulcer and urethral pathogens in men presenting with genital ulcer syndrome to primary health care clinics in South Africa. Sex Transm Dis. 2012;39(11):880-5.

18. Boily MC, Baggaley RF, Wang L, Masse B, White RG, Hayes RJ, Alary M. Heterosexual risk of HIV-1 infection per sexual act: systematic review and meta-analysis of observational studies. Lancet Infect Dis. 2009:9(2):118-29.

19. World Health Organization: Prevention and treatment of HIV and other sexually transmitted infection among men who have sex with men and transgender people: Annexes. World Health Organization, Geneva, 2011. 
Available at: http://whqlibdoc.who.int/publications/2011/9789241501750_ eng_annexes.pdf.

20. Serwadda D, Gray RH, Sewankambo NK, Wabwire-Mangen F, Chen MZ, Quinn TC, Lutalo T, Kiwanuka N, Kigozi G, Nalugoda F, et al. Human immunodeficiency virus acquisition associated with genital ulcer disease and herpes simplex virus type 2 infection: a nested case-control study in Rakai, Uganda. J Infect Dis. 2003;188(10):1492-7.

21. Freeman EE, Weiss HA, Glynn JR, Cross PL, Whitworth JA, Hayes RJ. Herpes simplex virus 2 infection increases HIV acquisition in men and women: systematic review and meta-analysis of longitudinal studies. AIDS. 2006; 20(1):73-83.

22. Burris H, Parkhurst J, Adu-Sarkodie Y, Mayaud P. Getting research into policy - herpes simplex virus type-2 (HSV-2) treatment and HIV infection: international guidelines formulation and the case of Ghana. Health Res Policy Syst. 2011;9(Suppl 1):S5. https://doi.org/10.1186/1478-4505-1189S1181-S1185.

23. Charurat ME, Emmanuel B, Akolo C, Keshinro B, Nowak RG, Kennedy S, Orazulike I, Ake J, Njoku O, Baral S et al: Uptake of treatment as prevention for HIV and continuum of care among HIV-positive men who have sex with men in Nigeria. J Acquir Immune Defic Syndr 2015, 68(Suppl 2):S114-S123. doi: 1https://doi.org/10.1097/QAl.0000000000000439.

24. Schwartz SR, Nowak RG, Orazulike I, Keshinro B, Ake J, Kennedy S, Njoku O, Blattner WA, Charurat ME, Baral SD. The immediate eff ect of the same-sex marriage prohibition act on stigma, discrimination, and engagement on HIV prevention and treatment services in men who have sex with men in Nigeria: analysis of prospective data from the TRUST cohort. Lancet HIV. 2015;2(7):e299-306.

25. World Health Organization. Guideline on when to start ART and on PrEP for HIV. Genevea, Switzerland; 2015. http://apps.who.int/medicinedocs/ documents/s22247en/s22247en.pdf.

26. Baral S, Logie CH, Grosso A, Wirtz AL, Beyrer C. Modified social ecological model: a tool to guide the assessment of the risks and risk contexts of HIV epidemics. BMC Public Health. 2013;13, 482. https://doi.org/10.1186/14712458-1113-1482

27. BA. R: Fundamentals of Biostatistics, vol. 4th edition. Duxbury; 1995

28. Wagenmakers EJ, Farrell S. AIC model selection using Akaike weights. Psychon Bull Rev. 2004;11(1):192-6.

29. Allman D, Adebajo S, Myers T, Odumuye O, Ogunsola S. Challenges for the sexual health and social acceptance of men who have sex with men in Nigeria. Cult Health Sex. 2007;9(2):153-68.

30. PrEP Watch. https://www.prepwatch.org. Accessed 15 Feb 2019

31. Stromdahl S, Onigbanjo Williams A, Eziefule B, Emmanuel G, Iwuagwu S, Anene O, Orazulike I, Beyrer C, Baral S. Associations of consistent condom use among men who have sex with men in Abuja, Nigeria. AIDS Res Hum Retrovir. 2012;28(12):1756-62.

32. Ruisenor-Escudero H, Grosso A, Ketende S, Pitche V, Simplice A, Tchalla J, Sodji D, Liestman B, Kapesa L, Baral S: Using a social ecological framework to characterize the correlates of HIV among men who have sex with men in Lome, Togo. AIDS Care 2017, 29(9):1169-1177. doi: 11101080/ 095401210954201701280122 Epub 09542017 Jan 09540129

33. Stromdahl S, Hickson F, Pharris A, Sabido M, Baral S, Thorson A. A systematic review of evidence to inform HIV prevention interventions among men who have sex with men in Europe. Euro Surveill. 2015;20(15).(pii):21096.

Ready to submit your research? Choose BMC and benefit from:

- fast, convenient online submission

- thorough peer review by experienced researchers in your field

- rapid publication on acceptance

- support for research data, including large and complex data types

- gold Open Access which fosters wider collaboration and increased citations

- maximum visibility for your research: over $100 \mathrm{M}$ website views per year

At BMC, research is always in progress.

Learn more biomedcentral.com/submissions 